\title{
A discrepancy between processing speed and verbal ability in gifted youth is genetically and diagnostically associated with autism
}

\author{
Jacob J. Michaelson ${ }^{1,2}$, Alissa Doobay ${ }^{3,4}$, Lucas Casten ${ }^{1}$, Megan Foley-Nicpon ${ }^{3,4}$, \\ Thomas Nickl-Jockschat ${ }^{1,2}$, Ted Abel ${ }^{1,2,5}$, Susan Assouline ${ }^{3,4}$
}

1. Department of Psychiatry, University of lowa, lowa City, IA, USA

2. lowa Neuroscience Institute, Carver College of Medicine, University of lowa, lowa City, IA, USA

3. Belin-Blank Center for Gifted and Talented Education, College of Education, University of lowa, lowa City, IA,

4. Department of Psychological and Quantitative Foundations, University of lowa, lowa City, IA, USA

5. Department of Neuroscience and Pharmacology, Carver College of Medicine, University of lowa, lowa City, IA, USA

\section{ABSTRACT}

Background: High cognitive ability is an almost universally positive prognostic indicator in the context of neurodevelopmental, neuropsychiatric, and neurodegenerative conditions. However, "twice-exceptional" individuals, those who demonstrate high cognitive ability (gifted) and also exhibit profound cognitive, behavioral, and mental health challenges, are a striking exception to this rule.

Methods: We digitized the clinical records of $\mathrm{N}=1,074$ clients from a US-based specialty clinic serving gifted students. This included a broad array of diagnostic, cognitive, achievement, and behavioral data, including self, teacher, and parent reported items. We conducted both hypothesis-driven and unsupervised learning analyses to 1) identify characteristics whose association with full-scale IQ (FSIQ) was dependent on autism diagnosis and 2) identify cognitive archetypes associated with autism diagnosis and related behaviors. We tested the generalization of our findings using data from the $A B C D$ study $(\mathrm{N}=10,602)$.

Results: Self-reported sense of inadequacy was most strongly associated with increasing FSIQ specifically among autistic clients (beta $=0.3,95 \% \mathrm{Cl}:[0.15,0.45]$, $\left.p=7.1 \times 10^{-5}\right)$. Similarly, self, parent, and teacher reports of anxiety increased with FSIQ (all $p<0.05$ ) in autistic individuals, in striking opposition to the ameliorating effect of FSIQ seen in non-autistic individuals. We uncovered a pattern of decreased processing speed (PS) coupled with very high verbal comprehension (VC), a PS/VC discrepancy, that was associated with autism, attention, and internalizing problems. These cognitivebehavioral links were also observed in the ABCD study. Finally, we found a significant association between the PS/VC discrepancy and polygenic risk for autism in the ABCD sample ( $\mathrm{t}=2.9, \mathrm{p}=0.004)$.

Conclusions: Our results suggest that highly elevated IQ with a significant PS/VC discrepancy is a clinically and genetically meaningful biotype linked to autism. 
medRxiv preprint doi: https://doi.org/10.1101/2021.11.02.21265802; this version posted November 4, 2021. The copyright holder for this preprint (which was not certified by peer review) is the author/funder, who has granted medRxiv a license to display the preprint in perpetuity. It is made available under a CC-BY-NC-ND 4.0 International license .

\section{INTRODUCTION}

The genetic loci that influence intelligence intersect with many known neurodevelopmental and psychiatric disorder genes (Zabaneh, Krapohl et al. 2018, Smeland, Bahrami et al. 2020). Yet the shared neurobiology underlying intelligence and psychiatric risk is still poorly understood. Whereas measurements of intelligence have evolved since their first documented uses, one through line of these assessments is the idea that general intelligence is comprised of distinct cognitive skill domains (Eling 2019). These domains typically include verbal comprehension (VC), perceptual reasoning $(\mathrm{PR})$, processing speed $(\mathrm{PS})$, working memory $(\mathrm{WM})$, and a composite score called a Full-Scale Intelligence Quotient (FSIQ). Studies of these scores have found that, overall, increased FSIQ is related to better outcomes and lower rates of psychiatric conditions and mental illness (Gale, Batty et al. 2010), but deficits in specific domains are related to an increased rate of psychiatric diagnoses (Williams, Goldstein et al. 2006).

Two specific intelligence domains of special interest to neurodevelopmental and psychiatric disorders are PS and VC. PS is typically defined as how efficiently the brain can take visual input, accurately decode that information, and produce a response. Measurement typically includes a proctored test involving a "key" set of patterns, with the subject identifying as many matches as possible in a short time period (Gomez, Vance et al. 2016). VC is commonly defined as the ability to understand concepts and effectively communicate (Gomez, Vance et al. 2016). Measurement of VC typically involves assessing vocabulary, ability to abstract similar words, and ability to understand complex expressions (Gomez, Vance et al. 2016). Studies of PS in autism have consistently found deficits across cohorts not seen in other neurodevelopmental conditions (Williams, Goldstein et al. 2006, Mayes and Calhoun 2008). Conversely, similar studies have sometimes found relative strengths in VC scores across neurodevelopmental and psychiatric disorders, including autism and bipolar disorder (Mayes and Calhoun 2008, Gale, Batty et al. 2013). However, the frequent co-morbidity of intellectual disability in these studies may contribute to inconsistent observation of a specific VC strength.

At the most extreme end of the cognitive discrepancy spectrum are "twice-exceptional" (2e) individuals, defined as having any IQ domain score greater than 120 (approximately the $91^{\text {st }}$ percentile) and a co-morbid neuropsychiatric diagnosis, like autism (Beckmann and Minnaert 2018). Thus, 2 e individuals may be an example of a population where high $\mathrm{IQ}$, particularly when it is unevenly distributed across domains of intelligence, may indicate a neurodevelopmental liability. Studying the relative strengths and weaknesses of $2 e$ individuals with autism could provide insights into how deficits in one specific intelligence domain may reflect disrupted neurobiology and identify pathways key to cognition and psychiatric risk.

Further evidence the neurobiology of intelligence and autism is intertwined comes from genetic studies. Twin studies of IQ have found it is one of the most heritable brain related traits, with a peak heritability estimate of $\sim 0.8$ in adulthood (Devlin, Daniels et al. 
medRxiv preprint doi: https://doi.org/10.1101/2021.11.02.21265802; this version posted November 4, 2021. The copyright holder for this preprint (which was not certified by peer review) is the author/funder, who has granted medRxiv a license to display the preprint in perpetuity. It is made available under a CC-BY-NC-ND 4.0 International license .

1997). Similarly high heritability estimates have been seen in autism, which is currently estimated at 0.8 (Bai, Yip et al. 2019). Genome Wide Association Studies (GWAS) for proxies of intelligence, like years of education, have identified over 1,200 associated genetic loci (Lee, Wedow et al. 2018). Examination of the genes implicated by these associated loci showed significant functional enrichment for processes known to be disrupted in autism, particularly in pathways related to dendrite morphology and neuronal migration (Lee, Wedow et al. 2018). Analyses of GWAS associations in intelligence and autism have found the two traits are significantly genetically correlated with each other (Grove, Ripke et al. 2019). Better characterization of the specific domains of intelligence impacted in autism could provide meaningful insights into the neurobiology underlying both autism and intelligence.

This study aims to answer the following questions: What behaviors, if any, become more problematic for autistic individuals with increasing IQ? Does an axis of discrepancy between PS and VC discriminate autism from other diagnoses? What are the behavioral correlates of the PS/VC discrepancy? Does the PS/VC axis predict similar behavioral issues in non-autistic individuals? Finally, what are the genetic correlates of this cognitive ability discrepancy? Answering these questions necessitates the study of twice-exceptional individuals with autism, who are likely to show more extreme cognitive discrepancies in PS and VC than autistic cohorts sampled without attention to IQ.

\section{METHODS AND MATERIALS}

Sample (Belin-Blank Center): Over a ten-year period (2009-2019), 1,254 children and adolescents ages six to 18 were evaluated at a university-based clinic that specializes in the assessment and counseling of gifted and twice-exceptional students. Some of the students were evaluated more than one time, which resulted in an analytic sample of $\mathrm{N}=1074$. Although students in the sample had Full Scale IQs as high as 158, a few of the clients evaluated at the clinic had very low IQs (e.g., 55). The average IQ for the sample was 116.9 (SD of 14.5), the median was 117. Some individuals in the sample were diagnosed with ASD, whereas others received a different diagnosis such as ADHD or SLD, and many did not have a diagnosis. Thus, from the perspective of cognitive ability, this sample provided a relatively normal IQ distribution compared to previously cited twice-exceptional research because the sample included individuals with very high IQ and diagnosed with ASD (twice-exceptional); as well as those with IQs that would be considered within the average range, or below, who were diagnosed with ASD (ASD/autistic); individuals with very high IQ and not diagnosed with ASD (gifted only); those with IQs within the average range, or below and not diagnosed with ASD (Average). Demographic information concerning the participants is presented in Table 1.

Sample (ABCD): The ABCD cohort (Lisdahl, Sher et al. 2018) is a typically-developing cohort, which was recruited regardless of neuropsychiatric conditions, meant to represent a more general population than case/control cohorts. Release 2 data were used. The cohort was further filtered to participants in which genetic data were available that passed our quality control and clustered in the majority European cluster based on 
medRxiv preprint doi: https://doi.org/10.1101/2021.11.02.21265802; this version posted November 4, 2021. The copyright holder for this preprint (which was not certified by peer review) is the author/funder, who has granted medRxiv a license to display the preprint in perpetuity. It is made available under a CC-BY-NC-ND 4.0 International license .

SNPs (genetic clustering detailed below). After this filtering, 6,559 ABCD participants remained.

The ABCD cohort was genotyped on the Affymetrix NIDA SmokeScreen Array and was processed through standard QC steps before release, including removing SNPs with low call rate and individuals with potential contamination problems or high missing data. The SNP QC process was based on the recommendations by (Marees, de Kluiver et al. 2018) using PLINK (Purcell, Neale et al. 2007) and R (R Core Team 2013) with the same parameters used for the SPARK genotyping QC. In total, 399,016 SNPs and 9,324 individuals passed QC. After this QC, the remaining cohort was merged and clustered with the 1,000 Genomes Phase 3. Clustering was based on the first 10 components from multi-dimensional scaling of the combined kinship matrix of the cohort and 1,000 Genomes. This combined cohort was clustered into 5 groups, representing the 5 distinct super-populations. For genotype imputation, ambiguous SNPs were also removed, leaving 372,694 SNPs. These remaining individuals and SNPs were imputed to the 1,000 Genomes Phase 3 ALL reference panel using the Genipe pipeline (Lemieux Perreault, Legault et al. 2016). 6,659 individuals clustered in the European cluster. Genipe performed LD calculation and pruning with PLINK (Purcell, Neale et al. 2007), genotype phasing with SHAPEIT (Delaneau, Marchini et al. 2011), and genotype imputation by IMPUTE2 (Howie, Donnelly et al. 2009) using default parameters.

Psychoeducational and diagnostic instruments: Sattler (Sattler 2018) offers a thorough description of the Wechsler Intelligence Scale for Children (5th Edition; WISCV). Multiple subtests comprise the WISC-V, including ten primary subtests: Block Design, Similarities, Matrix Reasoning, Digit Span, Coding, Vocabulary, Figure Weights, Visual Puzzles, Picture Span, and Symbol Search. From the ten primary subtests, the first seven are used to obtain the Full Scale IQ (FSIQ). In addition to the ten primary subtests, there are six secondary subtests as well as five complementary subtests. Scores from the Similarities and Vocabulary subtests comprise the Verbal Comprehension Index; Block Design and Visual Puzzles subtest scores comprise the Visual Spatial Index; Matrix Reasoning and Figure Weights subtest scores comprise the Fluid Reasoning Index; Digit Span and Picture Span comprise the Working Memory Index, and Coding and Symbol Search comprise the Processing Speed Index. The primary index scores as well as the $\mathrm{FSIQ}$, are reported as standard scores with a mean of 100 and a standard deviation of 15 . Standard scores for each of the scales have a mean score of 10 and a standard deviation of 3 .

The WISC-V (Wechsler 2014) is a widely used measure of intellectual ability with good psychometric properties (see the WISC-V Technical and Interpretive Manual; (Wechsler 2014)). Confirmatory factor analysis shows that the WISC-V measures five interrelated but distinct general abilities; thus, empirical data match the hypothesized structure of the test, which is rooted in contemporary intelligence theory (Wechsler 2014). Criterion validity studies demonstrate that the WISC-V can validly be interpreted as a measure of intelligence in children based on intercorrelations with the Kaufman Assessment Battery for Children (KABC-II; the WISC-V FSIQ and KABC-II Fluid Crystallized Index and Mental Processing Index were 0.77 to 0.81 , respectively), the Kaufman Test of 
medRxiv preprint doi: https://doi.org/10.1101/2021.11.02.21265802; this version posted November 4, 2021. The copyright holder for this preprint (which was not certified by peer review) is the author/funder, who has granted medRxiv a license to display the preprint in perpetuity. It is made available under a CC-BY-NC-ND 4.0 International license .

Educational Achievement (KTEA-3; most correlations were found to be within the Moderate range), the Wechsler Individual Achievement Test (WIAT-III; moderate correlations ranging from 0.40 to 0.73 were found between the WISC-5 FSIQ and WIAT-3 Composite scores), and the Wechsler Abbreviated Scale of Intelligence (WASIII; correlation coefficients are moderately high, ranging from 0.57 to 0.87 ). Test-retest reliability of the WISC-V is high, ranging from 0.88 (Processing Speed) to 0.96 (FSIQ and GAI). WISC-5 internal consistency estimates range from 0.81 to 0.94 ; for the $\mathrm{FSIQ}$, internal consistency across the 11 age groups ranged from 0.96 to 0.97 .

The Behavior Assessment System for Children, 3rd Edition (BASC-3; (Reynolds and Kamphaus 2015)) is described as "a multidimensional system used to evaluate the behavior and self-perceptions of children and young adults ages 2 through 25 years" (p.1). There are multiple components, including a self-report (SRP), a teacher-report (TRS), and a parent-report (PRS). Each of the three forms is further divided into Preschool (age 2-5), Child (ages 6 through 11 years), Adolescent (ages 12 through 18 years), and College (18-25) forms that contain similar subscales to facilitate comparisons between forms; for 6 - to 7 - year-old students, the self-report form is administered as an interview (SRP-I). Scores are reported as T-scores with a mean of 50 and standard deviation of 10. There are two types of scales: clinical scales (measuring behavioral and emotional concerns) and adaptive scales (measuring strengths or protective factors). Among the clinical scales, scores of 60 through 69 are considered At-Risk and scores of 70 and above are considered Clinically Significant. Among the adaptive scales, scores of 31 through 40 are considered At-Risk, whereas scores of 30 and below are considered Clinically Significant.

There is extensive research supporting the validity and reliability of the BASC-3 in clinical settings (Reynolds and Kamphaus 2015). Reliability measures across the TRS, PRS, and SRP suggest good internal consistency for both scale and composite scores. Median internal consistency for the BASC-3 TRS yielded alpha coefficients between .87 and .91 for the clinical and adaptive scales, and between .95 and .97 for the composite scales (Reynolds and Kamphaus 2015). Median internal consistency for the BASC-3 PRS yielded alpha coefficients between 0.83 and 0.89 for the clinical and adaptive scales, and between 0.93 and 0.97 for the composite scales (Reynolds and Kamphaus 2015). For the SRP, alpha coefficients were between 0.82 and 0.86 for the clinical and adaptive scales, and between 0.93 and 0.95 for the composite scales. Test-retest reliability was also high across the TRS, PRS, and SRP forms. Test-retest reliability for the TRS ranged from 0.87 to 0.91 for the clinical and adaptive scales, and from 0.95 to 0.97 for the composite scales. The PRS had test-retest reliabilities ranging from $0.83-$ 0.89 for the clinical and adaptive scales, and between 0.93 and 0.97 for the composite scales. For the SRP, the clinical and adaptive scales had test-retest coefficients between 0.82 and 0.86 , as well as composite scale coefficients between 0.93 and 0.95. The validity of the BASC-3 is substantially supported by the results of factor analyses consistent with scale composition, strong correlations with other instruments that assess emotional and behavioral symptoms in children (e.g., the Minnesota Multiphasic Personality Inventory and the Achenbach System of Empirically Based Assessment), and consistency between the results of this measure and the clinical diagnoses of the 
medRxiv preprint doi: https://doi.org/10.1101/2021.11.02.21265802; this version posted November 4, 2021. The copyright holder for this preprint (which was not certified by peer review) is the author/funder, who has granted medRxiv a license to display the preprint in perpetuity. It is made available under a CC-BY-NC-ND 4.0 International license .

child being assessed. Additionally, there is good consistency between the BASC-3 and previous versions of the BASC, which have been used in hundreds of research studies in various settings, countries, languages, and clinical populations (Reynolds and Kamphaus 2015).

All BASC-3 clinical and adaptive skills were included in the present analysis. The BASC-3 scales of interest in this study included the TRS, PRS, and SRP Anxiety scale, the TRS School Problems scale, the PRS Functional Communication and Attention Problems Scales, and the SRP Sense of Inadequacy Scale and Hyperactivity scales.

Statistical analysis: Both BASC and IQ scores were standardized (mean 0 and SD 1) within each decile of age. For each measure, Analysis of Variance (ANOVA; anova () and $\operatorname{Im}()$ functions in R version 3.3) was utilized to test the significance of main effects of ASD diagnosis and full-scale IQ, as well as their interaction. In the linear model underlying the ANOVA, individuals were re-weighted such that for individuals with FSIQ $<120$, their contribution to the least-squares fit was proportional to the pointwise estimate (based on their FSIQ) of density in a Gaussian distribution with mean 100 and SD 15. Collectively, individuals with $F S I Q>=120$ were each weighted the same, and the sum of these weights equaled the sum of the weights for individuals with $\mathrm{FSIQ}<$ 120. This reweighting has the effect of emphasizing individuals whose FSIQ is close to the mean of 100 , thus making the resulting comparisons with individuals with FSIQ > 120 more in line with what would be expected when comparing with a typical population sample. Although this approach had the effect of boosting power and resulted in a greater number of significant associations, in general the direction of association was congruent with an unweighted approach. The individual-level weights used in these analyses are included in Supplemental Table 1. For all ANOVA tests, adjustment for multiple testing was accomplished using the Benjamini-Hochberg procedure (Benjamini and Hochberg 1995) and is reported as false discovery rate (FDR) where applicable.

Unsupervised learning: We employed archetypal analysis (Cutler and Breiman 1994) as implemented in the archetypes package for R. Input features were the Z-scaled index scores and subtest scores of the WISC-IV and WISC-V. These were imputed with the median value where missing ( $12 \%$ missingness). To minimize the impact of outliers, the archetypal analysis procedure was trained on 5,000 random mixtures of the original data, where the original data matrix was multiplied by a random mixing matrix following a Poisson distribution with rate $=1$. The values of this random mixing matrix were normalized such that the contribution from each of the 1,074 individuals summed to 1 for each mixture. The archetypal coefficients for the observed data were then inferred using the predict () function of the archetypes $R$ package. The optimal number of archetypes was inferred using the elbow plot heuristic, which suggested diminishing returns after $\mathrm{k}=5$ archetypes. Individuals were assigned to archetypes using the following heuristic: briefly, an individual is assigned to an archetype if the coefficient for that archetype is the maximal coefficient for that individual and it is more than twice the next-highest archetypal coefficient. Those individuals who did not meet this criterion were grouped together in a "mixed" group. Subsequent analyses used archetype coefficients as explanatory variables in linear models testing association with 
medRxiv preprint doi: https://doi.org/10.1101/2021.11.02.21265802; this version posted November 4, 2021. The copyright holder for this preprint (which was not certified by peer review) is the author/funder, who has granted medRxiv a license to display the preprint in perpetuity. It is made available under a CC-BY-NC-ND 4.0 International license .

achievement and behavioral indices available in the database. To test association of the PS/VC discrepancy with BASC behavioral measures, we encoded a predictor variable as follows: 1 if the individual was assigned to A4, 3 if the individual was assigned to A5, and 2 for all others. This variable represents the ordinal progression from PS+/VC- (A4) to PS-/VC+ (A5). The models used for significance testing were therefore BASC sex + FSIQ + PS_VC, where BASC is the measure in question from the BASC, FSIQ is the fullscale IQ, and PS_VC is the ordinal variable described above.

Replication analysis: To determine whether key behaviors were robustly associated with a PS/VC discrepancy in an independent sample, we utilized data from the large ABCD study, a US-based general population study of adolescents with extensive behavioral, genetic, and neuroimaging data (Casey, Cannonier et al. 2018). Specifically, we constructed a PS/VC "discrepancy score" by multiplying participants' NIH toolbox scores for the pattern task (processing speed), the picture vocabulary task (verbal), and the reading task (verbal), by $-1,0.5$, and 0.5 , respectively, and then summing. These values were then Z-scaled to mean of 0 and standard deviation of 1 . Individuals with large positive values of this score would have a large PS/VC-type discrepancy similar to that observed in A5 in the B-BC sample (Fig. 3A). Likewise, ABCD participants with an extreme negative score would have a similar discrepancy to individuals belonging to the A4 archetype in the B-BC sample (Fig. 3A). We note that there would have been a number of ways to approach this analysis (e.g., factor analysis, canonical correlation analysis, etc.). We investigated these alternative approaches and found that they yielded similar findings to those described below. However, given that the PS/VC discrepancy score based on the simple difference in task scores is more straightforward and directly interpretable, we chose that in the end. To identify behavioral correlates of the PS/VC discrepancy in ABCD, we tested associations between the ABCD PS/VC discrepancy score and subscales of the Child Behavior Checklist (CBCL)(Achenbach, Becker et al. 2008). In total, twenty subscales derived from CBCL items are available in the $A B C D$ data release (see Figure 4C). We tested linear models of the form $y \sim \operatorname{sex}+$ total_comp + PS_VC, where y is the CBCL subscale score under investigation, total_comp is the NIH Toolbox total composite score, and PS_VC is the PS/VC discrepancy score described above.

\section{RESULTS}

\section{Anxiety and attention problems increase with FSIQ specifically in autistic} individuals. The primary motivating question for our diagnosis-driven analysis was to understand whether increasing IQ might in some way be a liability for those with an autism diagnosis, when compared both with their non-autistic, high IQ peers, as well as their autistic but average IQ peers. This goal was operationalized by examining the interaction term in a linear model of functional outcomes (from the BASC) predicted by autism diagnosis, full-scale IQ, and their interaction. Sex and age were included as additional covariates. As shown in Figure 2, we found that self-report of a sense of inadequacy had the strongest $A S D^{*} \mathrm{IQ}$ interaction (beta=0.3, 95\% Cl:[0.15,0.45], $\left.\mathrm{p}=7.1 \times 10^{-5}\right)$, indicating that autistic individuals show a 0.3 SD increase in this measure 
medRxiv preprint doi: https://doi.org/10.1101/2021.11.02.21265802; this version posted November 4, 2021. The copyright holder for this preprint (which was not certified by peer review) is the author/funder, who has granted medRxiv a license to display the preprint in perpetuity. It is made available under a CC-BY-NC-ND 4.0 International license .

for each SD increase in FSIQ. Furthermore, anxiety was a point of confluence between self (beta=0.15, 95\% Cl: [0.01,0.29]), parent (beta=0.17, 95\% Cl: [0.05,0.29]), and teacher report (beta $=0.14,95 \% \mathrm{Cl}:[0.02,0.27])$, though only parent report survived multiple testing correction at FDR $<0.05$ (see Figure 2 A-D). Other significantly associated (all FDR<0.05) outcomes include parent reported functional communication (beta $=-0.16,95 \% \mathrm{Cl}:[-0.27,-0.05])$ and attention problems (beta $=0.16,95 \% \mathrm{Cl}$ : $[0.05,0.27])$, teacher-reported school problems (beta=0.22, 95\% Cl: [0.07,0.37]), and self-reported hyperactivity (beta $=0.22,95 \% \mathrm{Cl}$ : $[0.06,0.38]$ ). To determine whether any of these associations would be considered potentially clinically meaningful, we dichotomized the BASC scores using the threshold of $>60$ (or $<40$ for reverse-scored variables). We found that teacher-reported school problems were nearly four times as likely to be clinically meaningful for an autistic individual with full-scale IQ of 120 vs. 100 $(\mathrm{OR}=4.2,95 \% \mathrm{Cl}$ : $[2.1,8.4])$. Similarly, self-reported sense of inadequacy was three times as likely to be clinically relevant for autistic individuals at FSIQ 120 vs. 100 $(\mathrm{OR}=2.9,95 \% \mathrm{Cl}:[1.4,5.9])$, and parent reported functional communication issues more than twice as likely $(\mathrm{OR}=2.3,95 \% \mathrm{Cl}:[1.6,3.5])$.

A discrepancy between processing speed (PS) and verbal comprehension (VC) is associated with autism. The central goal of our archetypal analysis was to uncover recurrent and distinct patterns of cognitive ability, and then determine whether any of those patterns are associated with autism diagnosis and other behaviors as observed from the BASC. This analysis is complementary to our diagnosis-driven analysis primarily because it utilizes an unsupervised learning approach and is agnostic to the diagnosis, which is only considered in a post-hoc analysis. Our analysis supported the presence of five cognitive archetypes in our sample (Figure 3). These archetypes correspond, approximately, to uniformly elevated ability (archetype 1, A1), generally lower ability with a specific strength in perceptual reasoning (archetype 2, A2), uniformly decreased ability (archetype 3, A3), strength in processing speed (PS) coupled with weakness in verbal comprehension (VC) (archetype 4, A4), and weakness in processing speed coupled with strength in verbal comprehension (archetype 5, A5). A total of 42 individuals did not meet criteria for exclusive assignment to any archetype and were considered "mixed". Summary statistics for each of these archetypes are provided in Table X. Notably, A4 and A5 are of particular interest because they are mirror images of each other (A4: PS+/VC- and A5: PS-/VC+) while further showing differential depletion and enrichment for autistic individuals, respectively (OR=0.39, 95\% $\mathrm{Cl}$ : $0.16,0.94]$ for $\mathrm{A} 4$ and $\mathrm{OR}=2.46,95 \% \mathrm{Cl}$ : $[1.5,4.1]$ for $\mathrm{A} 5)$.

PS/VC discrepancy is predictive of internalizing, attention, and other problems. Fourteen of 46 BASC measures were significantly associated with the PS/VC discrepancy at FDR $<0.05$, and the full summary statistics of these tests are available in Supplemental Table 1. Briefly, parent and teacher reports of withdrawal, teacherreported attention problems, parent- and teacher-reported atypicality, teacher-reported school problems, and teacher-reported depression were all significantly positively associated with PS/VC discrepancy (all FDR $<0.05$, see Supplemental Table 1). Parent reports of activities of daily living, parent- and teacher-reported social skills, parent- and teacher-reported leadership skills, teacher-reported functional communication, and 
medRxiv preprint doi: https://doi.org/10.1101/2021.11.02.21265802; this version posted November 4, 2021. The copyright holder for this preprint (which was not certified by peer review) is the author/funder, who has granted medRxiv a license to display the preprint in perpetuity. It is made available under a CC-BY-NC-ND 4.0 International license .

teacher-reported adaptability were all significantly negatively associated with PS/VC discrepancy all FDR $<0.05$, see Supplemental Table 1). Together, these results paint a picture of the PS/VC discrepancy contributing to problems with attention, internalizing issues (withdrawal, depression), poor leadership and social skills, and reduced adaptability, functional communication, and daily living skills. Notably absent are externalizing and somatization symptoms. Also noteworthy is the absence of association with any self-reported measures, which may suggest that those impacted by a PS/VC discrepancy may have little insight into the problems they face, while parents and teachers seem to be more attuned to these challenges.

\section{PS/VC discrepancy is predictive of internalizing and attention problems in the} ABCD sample. Nine of 20 available CBCL subscale scores showed a significant association at a nominal $p<0.05$. Summary statistics for the PS/VC discrepancy score association are found in Supplemental Table 1 and the corresponding results are presented in Figure 4. The most striking association of the PS/VC discrepancy is with the "sluggish cognitive tempo" (SCT) subscale of the CBCL (Achenbach, Becker et al. 2008) (beta=0.05 $t=5.2, p=2.6 \times 10^{-7}$ ). This association, together with other significant associations with attention and ADHD-related subscales, suggest that PS/VC discrepancy is strongly associated with attention issues, in agreement with the findings from our analysis of the B-BC sample. Further, we found that ABCD PS/VC is associated with a variety of internalizing symptoms, captured in the anxious/depressed, internalizing, and anxiety disorder subscales of the CBCL (all $p<0.05$ ). Again, this connection of internalizing symptoms with PS/VC discrepancy is consistent with our findings in the B-BC sample. Finally, a number of other subscale associations align with observations seen in the B-BC sample: associations between PS/VC and OCD and thought problem subscales of the CBCL are congruent with the increased atypicality linked to $A 5$ in the B-BC sample, and the association with total problems $(p<0.05)$ may reflect the functional and daily living associations found in the B-BC sample. Overall, these analyses suggest a general convergence of the PS/VC cognitive discrepancy onto a combination of attention problems, internalizing symptoms, and atypicality.

PS/VC discrepancy is associated with polygenic risk for autism. Although the above analysis established the robustness of the behavioral associations with PS/VC discrepancy in an independent sample, replicating the observed enrichment (A5) and depletion (A4) of autism diagnosis is more challenging: ABCD does not have reliable diagnosis information that can be used to robustly identify participants with ASD. Instead, we appealed to the genetic data in ABCD to determine whether individuals with high polygenic risk for autism showed an elevated PS/VC. Indeed, autism PRS is significantly associated with PS/VC (beta=0.07, $\mathrm{t}=2.9, \mathrm{p}=0.004$ ), in agreement with our observation in the B-BC sample of a significant excess of autism in A5 (and depletion in A4). 


\section{It is made available under a CC-BY-NC-ND 4.0 International license.}

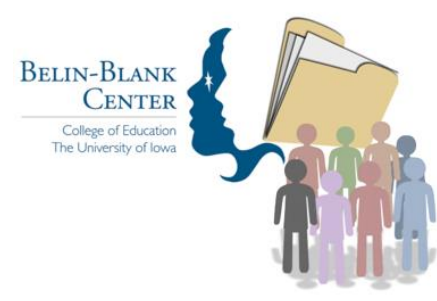

$\mathrm{N}=1,074$ gifted/talented clinical records

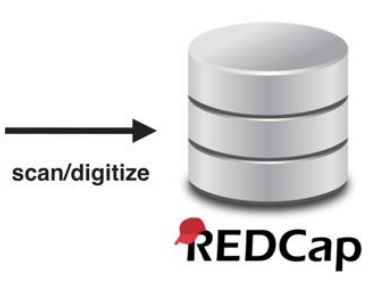

REDCap

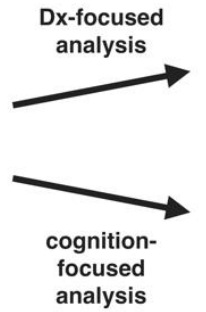

analysis

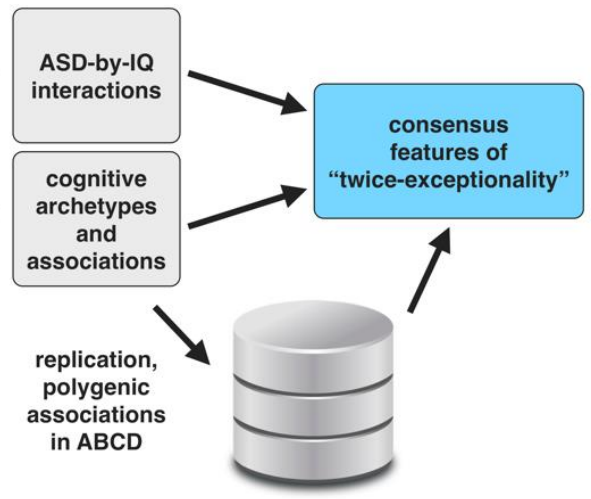

$A B C D$

Figure 1 - Overview of study design. Our discovery sample consisted of $\mathrm{N}=1,074$ clients seen at the Belin-Blank Center (B-BC), a specialty clinic at the University of lowa that serves gifted individuals. We digitized and entered the psychoeducational data from this sample into a REDCap database, which we then used to conduct hypothesis-driven and unsupervised learning analyses with the aim of gaining insight specifically into the cognitive, behavioral, and daily living challenges of "twice-exceptional" (2e) individuals: those with exceptional cognitive ability and having a diagnosis relevant to mental health. For the purposes of this study, we focus on autism, though twice-exceptionality extends beyond autism. Finally, to test the robustness and generalization of our findings, we used data from the ABCD study $(\mathrm{N}=10,601)$. We also used the genetic data in $\mathrm{ABCD}$ to compute polygenic risk scores for autism, which were then tested for association with traits of interest. 
medRxiv preprint doi: https://doi.org/10.1101/2021.11.02.21265802; this version posted November 4, 2021. The copyright holder for this preprint (which was not certified by peer review) is the author/funder, who has granted medRxiv a license to display the preprint in perpetuity.

It is made available under a CC-BY-NC-ND 4.0 International license .
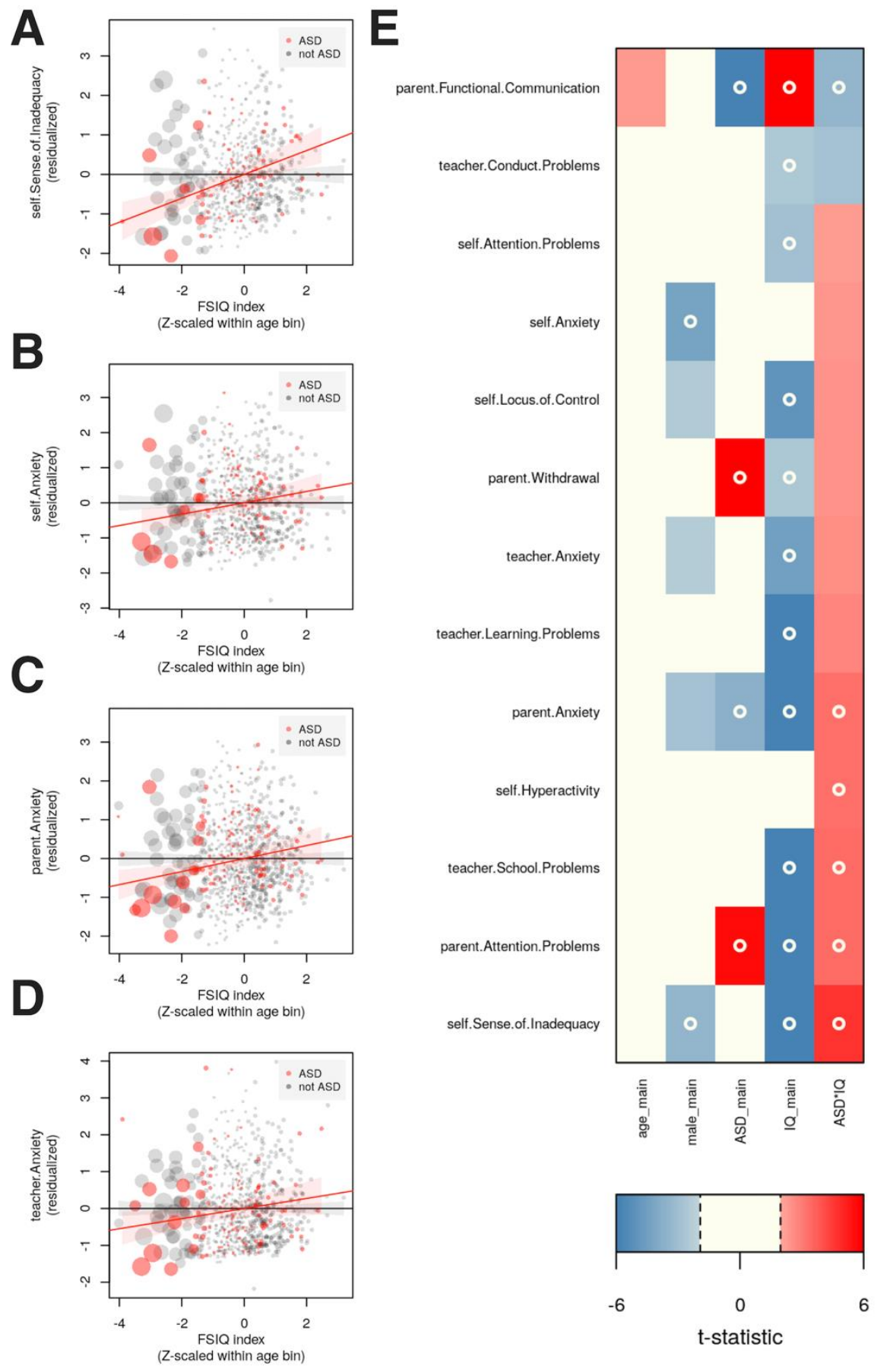

Figure 2 - Interactions between IQ and ASD diagnosis are associated with specific anxiety and attention -related problems. Using psychoeducational data from clinical records, we tested scores from the BASC for association with IQ, ASD diagnosis, and their interaction (with sex and age as additional covariates). Most strikingly, the interaction between ASD and IQ leads to an increased sense of inadequacy (A) as IQ increases in those diagnosed with ASD (red points). Similarly, increasing IQ in autistic individuals is associated with increased anxiety according to self (B), parent (C), and teacher report (D). The remaining tests of association are summarized in (E), where t-statistics are shown, with FDR $<0.05$ indicated by a circle. 
medRxiv preprint doi: https://doi.org/10.1101/2021.11.02.21265802; this version posted November 4, 2021. The copyright holder for this preprint (which was not certified by peer review) is the author/funder, who has granted medRxiv a license to display the preprint in perpetuity.

It is made available under a CC-BY-NC-ND 4.0 International license .
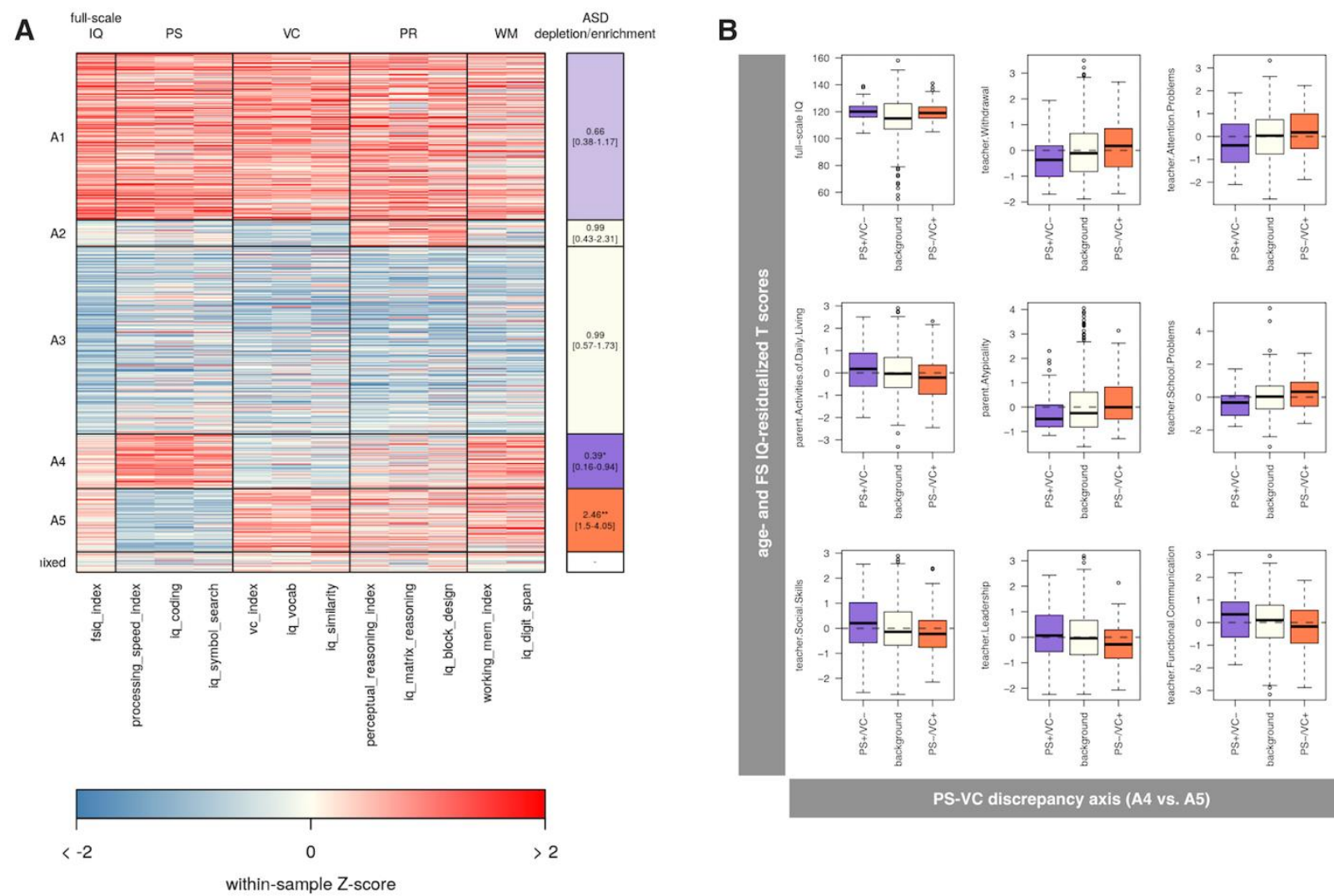

PS-vC discrepancy axis (A4 vs. A5)

Figure 3 - Unsupervised learning uncovers a discrepancy between processing speed (PS) and verbal comprehension (VC) that is significantly associated with autism diagnosis. We performed archetypal analysis, which yielded five distinct cognitive patterns or archetypes that best typify the patterns seen in the B-BC sample (A). In particular, archetype 4 (A4) and archetype 5 (A5) are nearly mirror-images of each other, with A5 showing a PS deficit and VC strength (PS-/VC+), and A4 showing a PS strength and VC deficit (PS+/VC-). A5 showed a significant over-representation of autistic individuals $(\mathrm{OR}=2.46,95 \% \mathrm{Cl}:[1.5,4.1])$, while A4 was significantly depleted (OR=0.39, $95 \% \mathrm{Cl}:[0.16,0.94])$. Taken together, this suggests an axis of risk and resilience, defined by a PS/VC discrepancy. We tested subscales from the BASC for association with the PS/VC discrepancy (B) to identify specific problem areas linked to this cognitive pattern, highlighting attention and internalizing problems similar to those identified in the diagnosis-driven analysis (see Figure 2). 
A

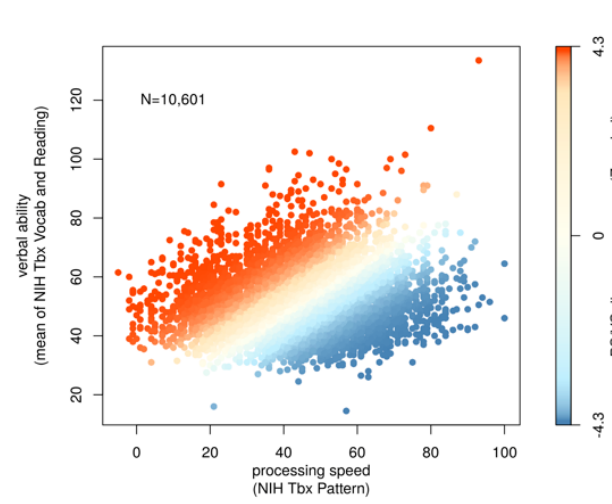

B

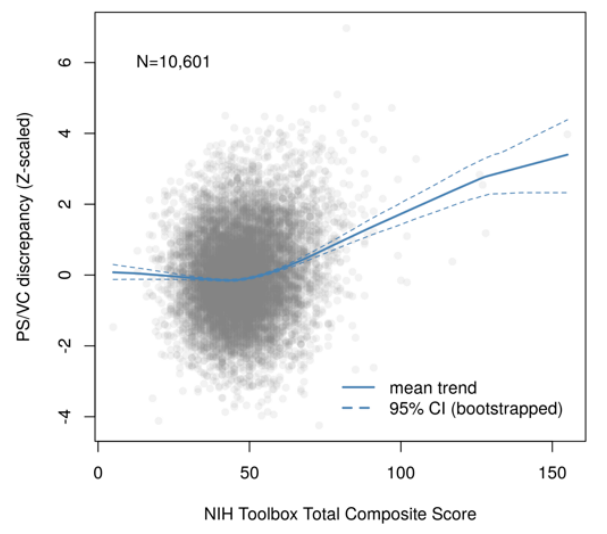

C

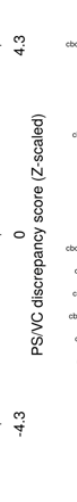

D

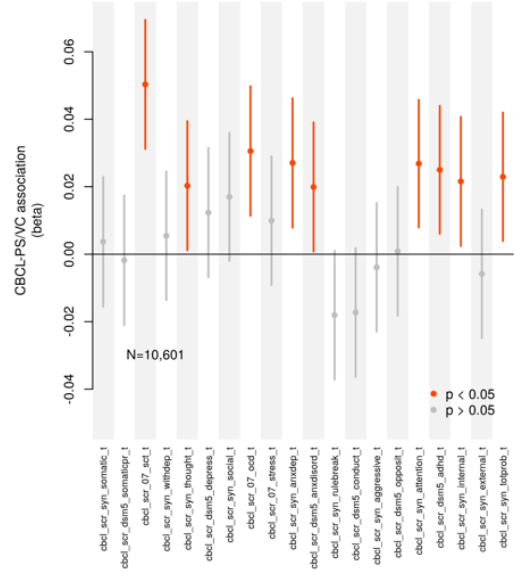

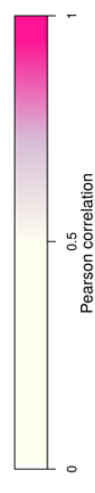

傐

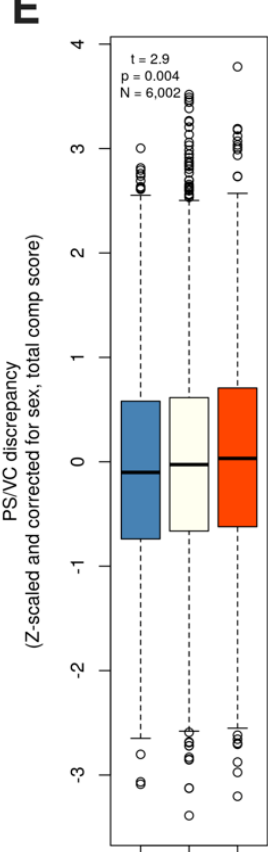

low med. high PRS PRS PRS

Figure 4 - Generalization and polygenic association of the PS/VC discrepancy in the ABCD study. We used scores from the $\mathrm{NIH}$ Toolbox available from ABCD to represent verbal comprehension (mean of vocabulary and reading tasks) and processing speed (pattern task) (A). The difference between verbal and processing speed scores (PS/VC discrepancy) was Z-scaled and is depicted in color in panel A. The PS/VC discrepancy score is positively correlated with the NIH Toolbox total composite score, but this effect is driven largely by individuals at the higher end of this score (B), suggesting that the PS/VC discrepancy is particularly relevant for individuals with high overall cognitive ability. Computed subscales from the CBCL are correlated with each other to varying degrees, and our clustering identified loose super-clusters of internalizing and externalizing subscales (C). These CBCL subscales were tested for association with the PS/VC discrepancy score in order to test the generalization of our observations from the B-BC sample (D). We found evidence suggesting that PS/VC is significantly associated with anxiety and other internalizing symptoms, as well as attention problems, in agreement with our initial findings. Finally, we found that $P S / V C$ is associated with increasing polygenic risk for autism (panel $E, p=0.004$ ), in agreement with our initial observation of over-representation of autism in A5 (the PS-/VC+ cognitive archetype, see Figure 3A). 


\section{References}

Achenbach, T. M., A. Becker, M. Dopfner, E. Heiervang, V. Roessner, H. C. Steinhausen and A. Rothenberger (2008). "Multicultural assessment of child and adolescent psychopathology with ASEBA and SDQ instruments: research findings, applications, and future directions." Journal of Child Psychology and Psychiatry 49(3): 251-275.

Bai, D., B. H. K. Yip, G. C. Windham, A. Sourander, R. Francis, R. Yoffe, E. Glasson, B. Mahjani, A. Suominen, H. Leonard, M. Gissler, J. D. Buxbaum, K. Wong, D. Schendel, A. Kodesh, M. Breshnahan, S. Z. Levine, E. T. Parner, S. N. Hansen, C. Hultman, A. Reichenberg and S. Sandin (2019). "Association of Genetic and Environmental Factors With Autism in a 5Country Cohort." JAMA Psychiatry 76(10): 1035-1043.

Beckmann, E. and A. Minnaert (2018). "Non-cognitive Characteristics of Gifted Students With Learning Disabilities: An In-depth Systematic Review." Front Psychol 9: 504.

Benjamini, Y. and Y. Hochberg (1995). "Controlling the False Discovery Rate - a Practical and Powerful Approach to Multiple Testing." Journal of the Royal Statistical Society Series BMethodological 57(1): 289-300.

Casey, B. J., T. Cannonier, M. I. Conley, A. O. Cohen, D. M. Barch, M. M. Heitzeg, M. E. Soules, T. Teslovich, D. V. Dellarco, H. Garavan, C. A. Orr, T. D. Wager, M. T. Banich, N. K. Speer, M. T. Sutherland, M. C. Riedel, A. S. Dick, J. M. Bjork, K. M. Thomas, B. Chaarani, M. H. Mejia, D. J. Hagler, Jr., M. Daniela Cornejo, C. S. Sicat, M. P. Harms, N. U. F. Dosenbach, M. Rosenberg, E. Earl, H. Bartsch, R. Watts, J. R. Polimeni, J. M. Kuperman, D. A. Fair, A. M. Dale and A. I. A. Workgroup (2018). "The Adolescent Brain Cognitive Development (ABCD) study: Imaging acquisition across 21 sites." Dev Cogn Neurosci 32: 43-54.

Cutler, A. and L. Breiman (1994). "Archetypal Analysis." Technometrics 36(4): 338-347.

Delaneau, O., J. Marchini and J. F. Zagury (2011). "A linear complexity phasing method for thousands of genomes." Nat Methods 9(2): 179-181.

Devlin, B., M. Daniels and K. Roeder (1997). "The heritability of IQ." Nature 388(6641): 468-471.

Eling, P. (2019). "History of Neuropsychological Assessment." Front Neurol Neurosci 44: 164178.

Gale, C. R., G. D. Batty, A. M. Mclntosh, D. J. Porteous, I. J. Deary and F. Rasmussen (2013). "Is bipolar disorder more common in highly intelligent people? A cohort study of a million men." Mol Psychiatry 18(2): 190-194.

Gale, C. R., G. D. Batty, P. Tynelius, I. J. Deary and F. Rasmussen (2010). "Intelligence in early adulthood and subsequent hospitalization for mental disorders." Epidemiology 21(1): 70-77.

Gomez, R., A. Vance and S. D. Watson (2016). "Structure of the Wechsler Intelligence Scale for Children - Fourth Edition in a Group of Children with ADHD." Front Psychol 7: 737.

Grove, J., S. Ripke, T. D. Als, M. Mattheisen, R. K. Walters, H. Won, J. Pallesen, E. Agerbo, O. A. Andreassen, R. Anney, S. Awashti, R. Belliveau, F. Bettella, J. D. Buxbaum, J. BybjergGrauholm, M. Baekvad-Hansen, F. Cerrato, K. Chambert, J. H. Christensen, C. Churchhouse, K. 
Dellenvall, D. Demontis, S. De Rubeis, B. Devlin, S. Djurovic, A. L. Dumont, J. I. Goldstein, C. S. Hansen, M. E. Hauberg, M. V. Hollegaard, S. Hope, D. P. Howrigan, H. Huang, C. M. Hultman, L. Klei, J. Maller, J. Martin, A. R. Martin, J. L. Moran, M. Nyegaard, T. Naerland, D. S. Palmer, A. Palotie, C. B. Pedersen, M. G. Pedersen, T. dPoterba, J. B. Poulsen, B. S. Pourcain, P. Qvist, K. Rehnstrom, A. Reichenberg, J. Reichert, E. B. Robinson, K. Roeder, P. Roussos, E. Saemundsen, S. Sandin, F. K. Satterstrom, G. Davey Smith, H. Stefansson, S. Steinberg, C. R. Stevens, P. F. Sullivan, P. Turley, G. B. Walters, X. Xu, C. Autism Spectrum Disorder Working Group of the Psychiatric Genomics, Bupgen, C. Major Depressive Disorder Working Group of the Psychiatric Genomics, T. andMe Research, K. Stefansson, D. H. Geschwind, M. Nordentoft, D. M. Hougaard, T. Werge, O. Mors, P. B. Mortensen, B. M. Neale, M. J. Daly and A. D. Borglum (2019). "Identification of common genetic risk variants for autism spectrum disorder." Nat Genet 51(3): 431-444.

Howie, B. N., P. Donnelly and J. Marchini (2009). "A flexible and accurate genotype imputation method for the next generation of genome-wide association studies." PLoS Genet 5(6): e1000529.

Lee, J. J., R. Wedow, A. Okbay, E. Kong, O. Maghzian, M. Zacher, T. A. Nguyen-Viet, P. Bowers, J. Sidorenko, R. Karlsson Linner, M. A. Fontana, T. Kundu, C. Lee, H. Li, R. Li, R. Royer, P. N. Timshel, R. K. Walters, E. A. Willoughby, L. Yengo, T. andMe Research, Cogent, C. Social Science Genetic Association, M. Alver, Y. Bao, D. W. Clark, F. R. Day, N. A. Furlotte, P. K. Joshi, K. E. Kemper, A. Kleinman, C. Langenberg, R. Magi, J. W. Trampush, S. S. Verma, Y. Wu, M. Lam, J. H. Zhao, Z. Zheng, J. D. Boardman, H. Campbell, J. Freese, K. M. Harris, C. Hayward, P. Herd, M. Kumari, T. Lencz, J. Luan, A. K. Malhotra, A. Metspalu, L. Milani, K. K. Ong, J. R. B. Perry, D. J. Porteous, M. D. Ritchie, M. C. Smart, B. H. Smith, J. Y. Tung, N. J. Wareham, J. F. Wilson, J. P. Beauchamp, D. C. Conley, T. Esko, S. F. Lehrer, P. K. E. Magnusson, S. Oskarsson, T. H. Pers, M. R. Robinson, K. Thom, C. Watson, C. F. Chabris, M. N. Meyer, D. I. Laibson, J. Yang, M. Johannesson, P. D. Koellinger, P. Turley, P. M. Visscher, D. J. Benjamin and D. Cesarini (2018). "Gene discovery and polygenic prediction from a genomewide association study of educational attainment in 1.1 million individuals." Nat Genet 50(8): 1112-1121.

Lemieux Perreault, L. P., M. A. Legault, G. Asselin and M. P. Dube (2016). "genipe: an automated genome-wide imputation pipeline with automatic reporting and statistical tools." Bioinformatics 32(23): 3661-3663.

Lisdahl, K. M., K. J. Sher, K. P. Conway, R. Gonzalez, S. W. Feldstein Ewing, S. J. Nixon, S. Tapert, H. Bartsch, R. Z. Goldstein and M. Heitzeg (2018). "Adolescent brain cognitive development (ABCD) study: Overview of substance use assessment methods." Dev Cogn Neurosci 32: 80-96.

Marees, A. T., H. de Kluiver, S. Stringer, F. Vorspan, E. Curis, C. Marie-Claire and E. M. Derks (2018). "A tutorial on conducting genome-wide association studies: Quality control and statistical analysis." Int J Methods Psychiatr Res 27(2): e1608.

Mayes, S. D. and S. L. Calhoun (2008). "WISC-IV and WIAT-II profiles in children with highfunctioning autism." J Autism Dev Disord 38(3): 428-439.

Purcell, S., B. Neale, K. Todd-Brown, L. Thomas, M. A. Ferreira, D. Bender, J. Maller, P. Sklar, P. I. de Bakker, M. J. Daly and P. C. Sham (2007). "PLINK: a tool set for whole-genome association and population-based linkage analyses." Am J Hum Genet 81(3): 559-575. 
medRxiv preprint doi: https://doi.org/10.1101/2021.11.02.21265802; this version posted November 4, 2021. The copyright holder for this preprint (which was not certified by peer review) is the author/funder, who has granted medRxiv a license to display the preprint in perpetuity.

It is made available under a CC-BY-NC-ND 4.0 International license .

R Core Team (2013). R: A Language and Environment for Statistical Computing. Vienna, Austria, R Foundation for Statistical Computing.

Reynolds, C. R. and R. W. Kamphaus (2015). BASC 3: Behavior Assessment System for Children (3rd Edition) Manual. Bloomington, MN, Psych-Corp, NCS Pearson.

Sattler, J. M. (2018). Assessment of Children: Cognitive Foundations and Applications. La Mesa, $\mathrm{CA}$, Jerome Sattler Publications.

Smeland, O. B., S. Bahrami, O. Frei, A. Shadrin, K. O'Connell, J. Savage, K. Watanabe, F. Krull, F. Bettella, N. E. Steen, T. Ueland, D. Posthuma, S. Djurovic, A. M. Dale and O. A. Andreassen (2020). "Genome-wide analysis reveals extensive genetic overlap between schizophrenia, bipolar disorder, and intelligence." Mol Psychiatry 25(4): 844-853.

Wechsler, D. (2014). Wechsler Intelligence Scale for Children (5th Edition). San Antonio, TX, NCS Pearson.

Wechsler, D. (2014). Wechsler Intelligence Scale for Children (5th Edition) Technical and Interpretive Manual. San Antonio, TX, NCS Pearson.

Williams, D. L., G. Goldstein and N. J. Minshew (2006). "Neuropsychologic functioning in children with autism: further evidence for disordered complex information-processing." $\underline{\text { Child }}$ Neuropsychol 12(4-5): 279-298.

Zabaneh, D., E. Krapohl, H. A. Gaspar, C. Curtis, S. H. Lee, H. Patel, S. Newhouse, H. M. Wu, M. A. Simpson, M. Putallaz, D. Lubinski, R. Plomin and G. Breen (2018). "A genome-wide association study for extremely high intelligence." Mol Psychiatry 23(5): 1226-1232. 